\title{
Influence of cigarette smoking on endoscopic sinus surgery long-term outcomes*
}

\author{
Antoni Krzeski ${ }^{1}$, Anna Galewicz ${ }^{1,2}$, Rafał Chmielewski ${ }^{1,3}$, Marta Kisiel ${ }^{1,4}$ \\ 1 Department of Otolaryngology, Warsaw Medical University, Warsaw, Poland \\ 2 Department of Otolaryngology, Stomatology Division, Czerniakowski Hospital, Warsaw Medical \\ University, Warsaw, Poland \\ 3 Department of Descriptive and Clinical Anatomy, Center of Biostructure Research, Warsaw Medical \\ University, Poland \\ 4 Division of Polymer Chemistry, Department of Materials Chemistry, Uppsala, Sweden
}

SUMMARY Objective: The purpose of this study was to explore the influence of smoking on long-term outcomes of endoscopic sinus surgery for chronic rhinosinusitis.

Methods: The study prospectively enrolled 274 patients at the Department of Otolaryngology of the Warsaw Medical University from 1993 to 2000. All patients were diagnosed with chronic rhinosinusitis and scheduled for the endoscopic sinus surgery. We evaluated subgroups of patients with respect to bronchial asthma, allergy, aspirin triad, gastro-esophageal reflux disease and nasal septal deviation. Patients were divided into smokers and non-smokers. Patient CT scan results were recorded according to the fourgrade classification system by Kennedy. Patients were observed over a period between 2 to 9 years following the surgical intervention and had their surgery revised if the severity of symptoms were at the same level or worsened.

Results: Prior to endoscopic sinus surgery, 23\% of smokers and 20\% of non-smokers scored III or IV on the Kennedy Scale. The revision ESS was carried out in 27 patients. In this group there were 20\% smokers and 7\% non-smokers, with the difference being significant. There was no significant difference in the postoperative quality of life scale scores.

Conclusions: The study shows that while smoking did not influence preoperative symptoms, smokers had worse postoperative outcomes.

Key words: smoking, FESS, CRS, long-term outcomes

\section{INTRODUCTION}

According to the World Health Organization (2005), in Poland $35.5 \%$ of the population $(27.20 \%$ female, $43.90 \%$ male $)$ are smokers ${ }^{(1)}$. Despite of current anti-tobacco campaigns, many people do not understand the seriousness of the health-related side effects of tobacco use and continue to smoke. Tobacco use has been proven as an independent risk factor of numerous diseases. Furthermore, smoking leads to postoperative complications in all surgical outcomes, including negative influence on the endoscopic sinus surgery in patients with Chronic Rhinosinusitis $(\mathrm{CRS})^{(2)}$. The pathophysiology of this process has not been fully explored.

To better understand the process itself, a few studies have focused on the molecular mechanisms of tobacco smoke, and its effect on the nasal cavity epithelium ${ }^{(3)}$. Cigarette smoke affects mucociliary clearance, reducing the secretion production and leading to inflammation. Yee et al. reported the presence of four different patterns of the nasal mucosa in patients suffering from CRS ${ }^{(4)}$. Another study by the same author compared the prevalence of each of those patterns in smokers and non-smokers, but showed no differences ${ }^{(5)}$. Furthermore, no relationship between the type of pattern and the cigarette packyear was reported. Biopsies of CRS mucosa demonstrated remodelling changes with an abnormal increase in squamous epithelium metaplasia, which mimicked nasal occlusion ${ }^{(6)}$. Similar findings were detected in lungs ${ }^{(7-9)}$. Animal studies of bronchial mucosa have demonstrated the beneficial role of this process. Metaplasia may protect other cells from injury and augment the restitution of the proper ciliated epithelium ${ }^{(10)}$. 
CRS, according to the current definition proposed by the European Rhinologic Society in the European Position Paper on Chronic Rhinosinusitis (EPOS), is a group of disorders characterized by inflammation of the nasal and paranasal sinuses mucosa, and is identified by two or more physical signs, with one being nasal obstruction or anterior / posterior nasal drip. Such symptoms must be unremitting for more than 12 consecutive weeks ${ }^{(11)}$.

Factors that are believed to contribute to CRS include allergy, immunological and endocrine disorders, craniofacial anatomical defects and external factors such as infections, air pollution and medications ${ }^{(3,12)}$. At this time, exposure to tobacco is of uncertain significance in the evaluation and treatment of CRS ${ }^{(12-14)}$.

CRS is one of the most common medical conditions and a reason for seeking professional medical help year round ${ }^{(15)}$. For this reason, treatment in the early stage of the disease is very important, starting with medical therapy including inhaled nasal steroids, nasal saline irrigation and antibiotics (in case of purulent discharge on nasal endoscopy). Patients qualify for sinus surgery if CRS cannot be controlled with the maximum medical therapy after a period of 3 months ${ }^{(11,16)}$. Sinus surgery restores the normal anatomical condition and drainage of the sinuses (by opening of the ostio-meatal complexes) and simultaneously removing a source of infection. The concept of the functional endoscopic sinus surgery (ESS) was introduced by Messerklinger in the early 1980's. Professor Antoni Krzeski was the first who applied this technique in Poland, in the Otolaryngology Department of the Warsaw Medical University in $1993^{(17)}$.

The objective of the study was to evaluate the influence of smoking on long-term outcomes of endoscopic sinus surgery for CRS.

\section{MATERIALS AND METHODS}

\section{Patients}

In this study, 274 patients were prospectively enrolled. They were referred to the Otolaryngology Department of Warsaw Medical University between January 1993 and December 2000 for the ESS to treat CRS. Informed consent was obtained from all participants. The research protocol was approved by the Ethics Committee of Warsaw Medical University. We evaluated several subgroups of patients with respect to: bronchial asthma, allergy, aspirin triad, gastro-esophageal reflux disease and nasal septal deviation (Table 1). In our questionnaire, we used 14 disease-specific and general questions (Table 2). They were based on the Rhinosinusitis Outcomes Measure scale (RSOM-31), though the set of questions we chose had not been validated. Symptoms were recorded on a 4 -grade scale $(0-$ not present, 1 - mean, 2 - moderate and 3 - severe) and the average score was counted for each patient. For further analysis, 6 symptoms of the most significant severity were chosen. The improvement score for each of those symptoms was calculated immediately postoperatively, and from 2 to 9 years after the ESS (Table 3).
Smoking behaviors were among the data evaluated. With regards to this, patients were divided into smokers and nonsmokers. Patients were considered smokers if they reported any tobacco smoking at the time of ESS. Passive smokers (having any exposure to cigarettes in the household) and former smokers were included into the nonsmokers group. The survey was repeated postoperatively. The surgical results of smokers and non-smokers were compared. The total average pre- and postoperative results obtained in the smoking and non-smoking groups were compared. Furthermore, the preoperative paranasal sinus CT of each patient was recorded on the four grades Kennedy Scale ${ }^{(20)}$. Number of smokers and non-smokers with bilateral ethmoiditis and inflammation of two or more sinuses on each sides and/or extensive nasal polyposis (score III and IV) were compared. In cases of revision ESS, patients were reevaluated by the same means, and revision surgery rates in both groups were calculated.

\section{Study design}

In accordance to the European Otolaryngology Society criteria, patients were qualified to receive ESS if they failed to respond to the maximal medical treatment. Response failure was diagnosed when two or more symptoms (including nasal obstruction and posterior nasal drip) persisted for more than 12 consecutive weeks ${ }^{(18)}$. Prior to surgery, patients were evaluated by the sinonasal symptoms survey, physical examination including rigid or flexible nasal endoscopy and computed tomography (CT) scan. Postoperative follow-up on average was 4 years and 5 months (ranging from 2 to 9 years).

\section{Statistical analysis}

The statistical analysis of the raw data was performed with the Statistica 6 software. Categorical data were described by percentages and compared using Chi-square test. Continuous descriptive data were described by means with standard deviation (SD) or range. The Student's t-test was used to compare continuous outcomes variables.

The ANOVA test was used to evaluate the significance of outcomes. Statistical significance was accepted as $\mathrm{p} \leq 0.05$.

\section{RESULTS}

In the total group of 274 patients who met the inclusion criteria, women outnumbered men ( $52 \%$ were female). The age ranged from 13 to 67 years. All patients were diagnosed with CRS and underwent the primary ESS. We evaluated subgroups of patients with respect to bronchial asthma, allergy, aspirin triad, gastro-esophageal reflux disease and nasal septal deviation. Numbers of patients and the percentages are summarized in Table 1. Sixty percent of the patients had been scheduled for the surgery more than 5 years after they developed the first CRS symptoms and only $5 \%$ of the patients has been operated within a year from the onset of CRS. Full data on the time between onset of symptoms and the ESS is summarized in Table 4. Table 5 demonstrates patients' characteristics with regard to the preoperative symptoms of significant severity. Six symptoms have received the highest severity scores, 
Table 1. Patients' characteristics in respect to the accompanying medical conditions $(n=274)$.

\begin{tabular}{lc}
\hline Accompanying condition & $\begin{array}{c}\text { Number of patients } \\
\text { (percentage) }\end{array}$ \\
\hline Septal deviation & $136(50 \%)$ \\
Perennial Allergy & $88(32 \%)$ \\
GERD & $82(30 \%)$ \\
Bronchial asthma & $79(29 \%)$ \\
Nasal polyposis \\
(grade IV in Kennedy's Scale) & $76(28 \%)$ \\
Seasonal Allergy & $41(15 \%)$ \\
Aspirin triad & $19(7 \%)$ \\
\hline
\end{tabular}

Table 2. Symptoms criteria used in the study.

Nasal Blockage/ Congestion
Thick Nasal Discharge
Nasal Purulent/ Muco-Purulent Discharge
Post-Nasal Drip
Pain/ Pressure In Eye Corner
Facial Pain/ Pressure
Headache
Pain of Temporal Region
Hypoosmia/ Asomia
Wake up Tired
Irritable/ Frustrated
Reduced Concentration
Ear Fullness/ Blockage
Others (Sad, Reduced Productivity)

Table 3. Selective symptoms severity before the ESS and improvement after the ESS (immediately, after 2 and 9 years).

\begin{tabular}{lcccc}
\hline \multirow{2}{*}{ Symptom } & \multirow{2}{*}{$\begin{array}{c}\text { Mean symptom severity } \\
\text { before the ESS }\end{array}$} & immediately after the ESS & 2 years after the ESS & 9 years after the \\
\cline { 3 - 5 } & & 2.03 & 1.89 & 1.4 \\
\hline Nasal blockage & 2.6 & 1.06 & 1.05 & 1.02 \\
Loss of smell & 2.33 & 1.24 & 1.31 & 1.59 \\
Frontal headache & 2.27 & 1.13 & 1.08 & 0.9 \\
Postnasal drip & 2.21 & 1.29 & 1.26 & 1.15 \\
Muco-purulent rhinorrhea & 2.19 & 0.92 & 0.97 & 1.17 \\
Watery rhinorrhea & 2.03 & & \\
\hline
\end{tabular}

with the first three being the nasal blockage, the loss of smell and the postnasal drip. Table 3 presents the ESS results in regard to the selective symptoms (as presented by the EPOS 2007), improvement immediately after the procedure, and in the 2 and 9 years follow-up evaluation. The pronounced CT changes (III and IV grade in the Kennedy's Scale) were most characteristic for the patients with accompanying aspirin triad (95\%), bronchial asthma (68\%) and perennial allergy (60\%) - Table 6. The cohort was separated into the smokers and non-smokers groups (61 versus 213 - Figure 1). The preoperative sinonasal symptoms and quality of life questions analysis demonstrated no significant difference between the smokers and non-smokers $(\mathrm{p}=0.58)$. On the preparative Kennedy Scale, $24 \%$ of smokers and $20 \%$ of non-smokers scored III or IV, which is not a statistically significant difference $(p=0.7)$ (Figure 2). Evaluating the relative risk of the ESS failure, allergy (both perennial and seasonal) is not a revision ESS risk factor, while the smoking is (Table 7).

All patients who were active smokers at the time of the ESS continued smoking postoperatively. The revision ESS was carried out in 12 of the 61 smokers $(20 \%)$ and 15 of the 213 nonsmokers $(7 \%)$. We achieved a statistically significant difference $(\mathrm{p}=0.04)$ (Figure 3$)$. There was no significant difference between the smokers and non-smokers in the postoperative quality of life scale scores $(p=0.17)$, though the two symptoms with the most significant postoperative improvement in both groups were facial pain and concentration disturbances.

\section{DISCUSSION}

While the negative influence of tobacco smoking have been documented in different general and orthopaedic surgery interventions in adults ${ }^{(2,21)}$ and in the operated secretory otitis media children, whose parents were smokers ${ }^{(22)}$, the process itself is poorly understood in the upper aerodigestive tract. CRS is a multifactorial disease process, which makes it difficult to evaluate the influence of a single factor. Currently, smoking is one of the most emerging predictors of the CRS surgical outcome. The process has been investigated by a few, small studies so far ${ }^{(4-7,9,28,36)}$. Most of these studies were composed predominantly of retrospective reports with a low number of patients and a short follow-up. Our study is larger than all previous English-language papers published about correlation between the smoking behaviours and the life quality scores combined with the CT imaging scores. However, there are several limitations of our study, which has not been resolved yet.

We had only used a limited and not validated set of questions for the symptoms and the quality of life evaluation. When the study was initiated, there was no recommended scale available. To compare the treatment results, we decided to use the same scale across all years of the study. Over the last 10 years, subjective instruments have been progressively developed and nearly every published study has used different symptoms scales. The latest review of the patient reported outcome measures in rhinology was presented by Hopkins ${ }^{(19)}$. Our symptoms instrument included all potentially important major sinonasal complaints. 
Table 4. Time from the onset of symptoms to the ESS $(\mathrm{N}=274)$.

\begin{tabular}{cc}
\hline Years from the onset & $(\%$ of patients $)$ \\
\hline$<1$ & 5 \\
$1<2$ & 8 \\
$2<3$ & 10 \\
$3<5$ & 17 \\
$>5$ & 60 \\
\hline
\end{tabular}

Table 6. Grade of the CT changes (Kennedy's Scale scores) in respect to the accompanying medical conditions ( $\%$ of patients).

\begin{tabular}{lcc}
\hline Accompanying condition & I and II (\%) & III and IV (\%) \\
\hline Bronchial asthma & 32 & 68 \\
Perennial Allergy & 40 & 60 \\
Seasonal Allergy & 63 & 37 \\
Aspirin triad & 5 & 95 \\
GERD & 60 & 40 \\
Cigarette smoking & 76 & 24 \\
\hline
\end{tabular}

We demonstrated no differences in symptom improvement between smokers and non-smokers. We did not correlate the outcomes with the demographic characteristics of our population including gender, age and general health status, but we do believe that patients with higher educational level and easier access to medical care may have a lower tolerance for symptoms. Similar observations have been demonstrated and proved also in other human disorders ${ }^{(24)}$.

Even less is known about the influence of passive smoking on ESS outcomes in children with CRS. ESS in the pediatric population has been demonstrated to be safe and effective ${ }^{(25,26)}$. A recent study by Bernatowska et al. showed that the CRS pediatric patients had worse quality of life scores in comparison to the asthma patients ${ }^{(27)}$. Ramadan et al., reported a significantly lower treatment success rate in children who came from a smoking environment compared to those without the tobacco smoke exposure (70\% versus $90 \%){ }^{(28)}$. Another study on children with immature immune systems demonstrated that common factors may cause severe mucosal damage ${ }^{(29)}$.

In our study, we did not analyze the impact of smoking on specific symptoms, nor which symptoms tended to relapse after the initial treatment. Jorissen and Bachert presented the effects of topically administered corticosteroids on wound healing after the ESS ${ }^{(45)}$. They report $20 \%$ of patients experiencing an impaired wound healing following ESS. In most of those conditions, the use of modern topical corticosteroids is effective not only in reducing nasal symptoms but also having a histologically confirmed effect, with a tendency to reduce the thickness of the mucous membrane stroma, without impeding the epithelial differentiation. In our material as presented in Table 1, the percentage of 'complicated' patients may be as high as $30-50 \%$ of the population operated on if we consider
Table 5. Preoperative symptoms of significant severity (grade 3 in the scale- 0 - no symptom, 1 - mean, 2 - moderate, 3 - severe).

\begin{tabular}{lc}
\hline Symptom & (\% of patients) \\
\hline Nasal blockage & 60 \\
Loss of smell & 39 \\
Postnasal drip & 38 \\
Frontal headache & 35 \\
Watery rhinorrhea & 28 \\
Mucopurulent rhinorrhea & 28 \\
\hline
\end{tabular}

Table 7. The relative risk of ESS failure of the smokers and allergic patients ( $\%$ of patients).

\begin{tabular}{lcc}
\hline Condition & No revision & Revision ESS \\
\hline Perennial allergy & 32 & 33 \\
Seasonal allergy & 15 & 15 \\
Cigarette Smoking & 22 & 44 \\
\hline
\end{tabular}

factors such as accompanying bronchial asthma, GERD, perennial allergy or nasal septal deviation. A recent meta-analysis demonstrated that nasal obstruction was the symptom that improved the most, with facial pain having only a moderate change in severity ${ }^{(30)}$.

Additionally, the preoperative CT scans were evaluated using the Kennedy Scale, which was considered to be the most suitable as it was easy to apply and reproduce. The severity of symptoms correlates poorly with the abnormalities on the CT scan ${ }^{(31-34)}$. The predictive value of the CT score as it relates to the symptoms is not yet determined. It is used mostly as an additional factor in the decision-making process.

Senior et al., reported that smoking at the time of the ESS worsened outcomes. There were $27 \%$ of smokers in the revision surgery group in comparison to $10 \%$ of smokers in the group operated once $(p=0.19)$. Moreover, all smokers with the preoperative severe CT scan score had a revision surgery and worse results in the Sinus Nasal Outcome Test (SNOT16). Expecting worse postoperative outcomes, the authors suggested the exclusion of active smokers from the ESS ${ }^{(34)}$. Smith et al., demonstrated no significant relationship between smokers $(n=11)$ and non-smokers $(n=108)$ in preoperative CT scans $(\mathrm{p}=0.99)$, endoscopy $(\mathrm{p}=0.34)$ and preoperative and postoperative Chronic Sinusitis Survey Scores (CSSS) ( $p=$ 0.95). Those outcomes may have resulted from a relatively small group of smoking patients and a short follow-up (6 months) ${ }^{(15)}$. Briggs et al., reported that smoking caused poorer recovery in patients undergoing ESS ${ }^{(35)}$. In the material analysed by Das et al., there was no significant influence of preoperative smoking on the long-term postoperative outcomes. Smokers, however, had better postoperative quality of life score (SNOT-20) (mean 22.1 to 16.1 ) at short-term follow-up. The authors also noticed 


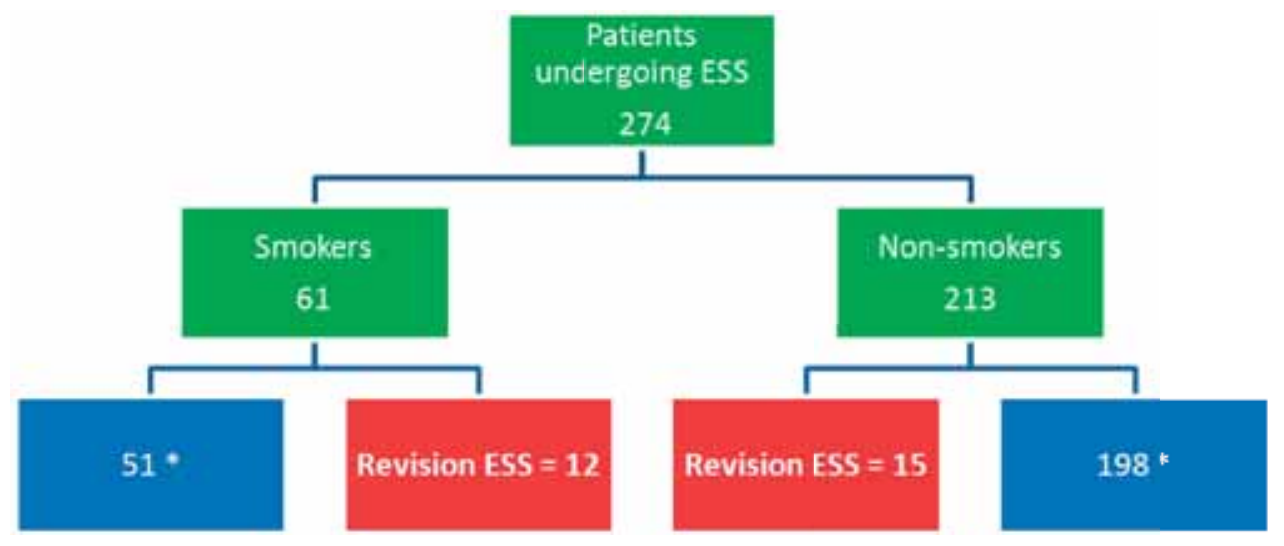

Figure 1. Patients demographics. Blue box - patients operated once.

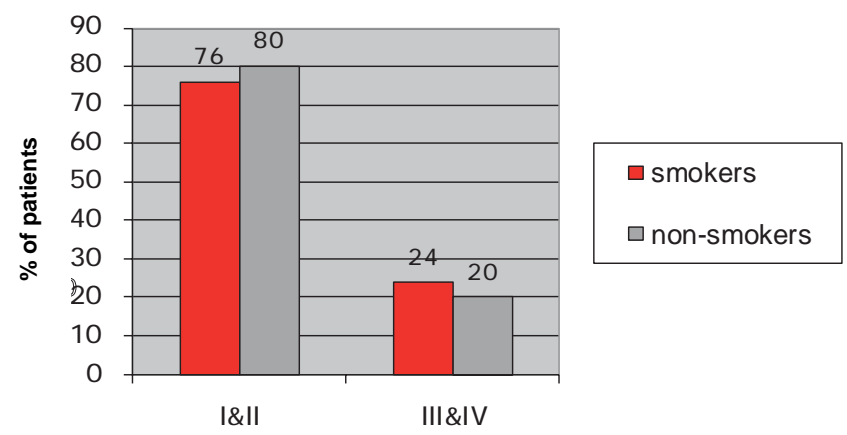

Figure 2. Preoperative CT scans scores of the smokers and non-smokers groups (Kennedy's Scale).

that postoperative smoking is a risk factor for worse postoperative outcomes ${ }^{(36)}$. As nasal polyposis raises the CT scale score, in our material, we have noticed higher rates of postoperative complications and higher rates of the revision surgeries. The group of patients with higher preoperative CT scale scores benefitted most from the surgery ${ }^{(23)}$. The extent of the surgery was usually correlated with higher CT scores ${ }^{(37)}$. Russell et al., demonstrated higher postoperative quality of life score in the smokers group with no differences between smokers and non-smokers groups preoperatively ${ }^{(35)}$. We did not compare the postoperative CT scan scores because these were not routinely performed.

In our study, we did not include the passive smokers in the smokers group. Bascom ${ }^{(38,39)}$ and Lieu et al., ${ }^{(40)}$ analyzed selfreported sinusitis in a large population and did not show a higher prevalence of illness in passive smokers, while this correlation was found in the smokers.

Several authors stated that the risk of complication is higher in the revision ESS ${ }^{(41,42)}$. Others reported no differences in the incidence of side effects between the primary ESS and the revision $\operatorname{ESS}^{(43,44)}$.

We showed that smoking habits did not influence the preoperative CT scan scores $(p=0.7)$, nor the pre/postoperative symptom scale scores $(p=0.57 / p=0.17)$. Nevertheless, there

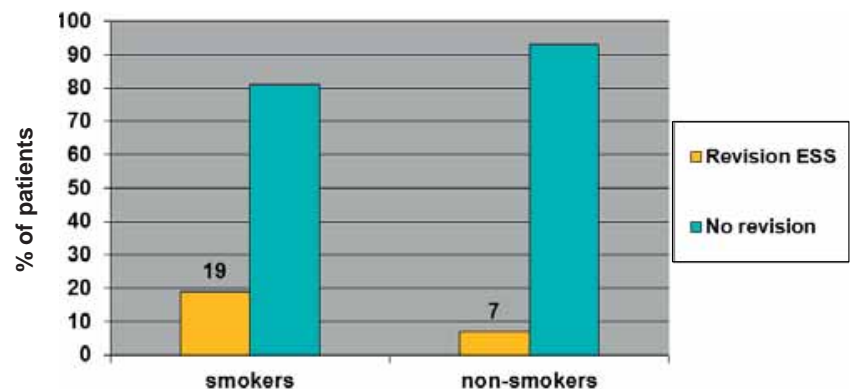

Figure 3. Proportion of the smokers and non-smokers who required and did not require the revision Endoscopic Sinus Surgery.

were twice more smokers in the revision surgery group than in the operated once group, which was significant $(p=0.04)$. We believe that the results of our study together with already published data support the recommendation of smoking cessation when CRS is diagnosed. Cooperation between the otorhinolaryngologists, general practitioners and the patient, together with education might markedly improve the treatment results. On the other hand, we do need more precise data from randomised prospective case-control studies to clarify the influence of tobacco smoking in the natural history of the CRS.

\section{CONCLUSIONS}

The study shows that while smoking did not influence preoperative symptoms, smokers had worse long-term postoperative outcomes.

\section{ACKNOWLEDGEMENTS}

The authors would like to thank Judith Grimmond, MD, Child and Adolescent Psychiatry Fellow (Department of Child and Adolescent Psychiatry, University of Missouri-Columbia) for her editorial assistance.

\section{REFERENCES}

1. InfoBase/Poland WHO 1974-2001 www.euro.wha.int

2. Moller AM, Villebro N, Pedersen T, Tonnesen H. Effect of preoperative smoking intervention on postoperative complications: a randomised clinical trial. Lancet 2002; 359: 114-117. 
3. Benninger MS, Ferguson BJ, Hadley JA, et al. Adult chronic rhinosinusitis: definitions, diagnosis, epidemiology, and pathophysiology. Otolaryngol Head Neck Surg. 2003; 129: S1-32.

4. Yee KK, Pribitkin EA, Cowart BJ, Rosen D, Feng P, Rawson NE. Analysis of the olfactory mucosa in chronic rhinosinusitis. Ann N Y Acad Sci. 2009; 1170: 590-595.

5. Yee KK, Pribitkin EA, Cowart BJ, et al. Smoking-associated squamous metaplasia in olfactory mucosa of patients with chronic rhinosinusitis. Toxicol Pathol. 2009; 37: 594-598.

6. Tamashiro E, Xiong G, Anselmo-Lima WT, Kreindler JL, Palmer JN, Cohen NA. Cigarette smoke exposure impairs respiratory epithelial ciliogenesis. Am J Rhinol Allergy. 2009; 23: 117-122.

7. Coggins CR. A review of chronic inhalation studies with mainstream cigarette smoke in rats and mice. Toxicol Pathol. 1998; 26: 307-314.

8. King PT, Holdsworth SR, Farmer M, Freezer N, Villanueva E, Holmes PW. Phenotypes of adult bronchiectasis: onset of productive cough in childhood and adulthood. COPD 2009; 6: 130-136.

9. Peters EJ, Morice R, Benner SE, Lippman S, Lukeman J, Lee JS, Ro JY, Hong WK. Squamous metaplasia of the bronchial mucosa and its relationship to smoking. Chest. 1993; 103: 1429-1432.

10. Park KS, Wells JM, Zorn AM, et al. Transdifferentiation of ciliated cells during repair of the respiratory epithelium. Am J Respir Cell Mol Biol. 2006; 34: 151-157.

11. Fokkens W, Lund V, Mullol J. European position paper on rhinosinusitis and nasal polyps 2007. Rhinol Suppl. 2007; 1-136.

12. Kennedy DW. Pathogenesis of chronic rhinosinusitis. Ann Otol Rhinol Laryngol Suppl. 2004; 193: 6-9.

13. Senior BA, Kennedy DW, Tanabodee J, Kroger H, Hassab M, Lanza DC. Long-term impact of functional endoscopic sinus surgery on asthma. Otolaryngol Head Neck Surg. 1999; 121: 66-68.

14. Sobol SE, Wright ED, Frenkiel S. One-year outcome analysis of functional endoscopic sinus surgery for chronic sinusitis. J Otolaryngol. 1998; 27: 252-257.

15. Smith TL, Mendolia-Loffredo S, Loehrl TA, Sparapani R, Laud PW, Nattinger AB. Predictive factors and outcomes in endoscopic sinus surgery for chronic rhinosinusitis. Laryngoscope 2005; 115 : 2199-2205.

16. Lanza DC, Kennedy DW. Adult rhinosinusitis defined. Otolaryngol Head Neck Surg. 1997; 117: S1-S7.

17. Krzeski A. Chirurgia endoskopowa zatok przynosowych - technika operacyjna. Otolaryngol Pol. 1997; LI, 1: 20-25.

18. European position paper on rhinosinusitis and nasal polyps. Rhinol Suppl. 2005; 1-87.

19. Hopkins C. Patient reported outcome measures in rhinology. Rhinology. 2009; 47; 10-17.

20. Kennedy DW. Prognostic factors, outcomes and staging in ethmoid sinus surgery. Laryngoscope. 1992; 102: 1-18.

21. Lindstrom D, Sadr AO, Wladis A, et al. Effects of a perioperative smoking cessation intervention on postoperative complications: a randomized trial. Ann Surg. 2008; 248: 739-745.

22. Hinton AE. Surgery for otitis media with effusion in children and its relationship to parental smoking. J Laryngol Otol. 1989; 103: 559-561.

23. Hopkins C, Browne JP, Slack R, Lund V, Brown P. The LundMackay staging system for chronic rhinosinusitis: how is it used and what does it predict? Otolaryngol Head Neck Surg. 2007; 137: 555-561.

24. Alonso J, Anto JM, Gonzalez M, Fiz JA, Izquierdo J, Morera J. Measurement of general health status of non-oxygen-dependent chronic obstructive pulmonary disease patients. Med Care. 1992; 30: MS125-MS135.

25. Lazar RH, Younis RT, Gross CW. Pediatric functional endonasal sinus surgery: review of 210 cases. Head Neck. 1992; 14: 92-98.

26. Gross CW, Gurucharri MJ, Lazar RH, Long TE. Functional endonasal sinus surgery (FESS) in the pediatric age group. Laryngoscope. 1989; 99: 272-275.

27. Cunningham JM, Chiu EJ, Landgraf JM, Gliklich RE. The health impact of chronic recurrent rhinosinusitis in children. Arch Otolaryngol Head Neck Surg. 2000; 126: 1363-1368.
28. Ramadan HH, Hinerman RA. Smoke exposure and outcome of endoscopic sinus surgery in children. Otolaryngol Head Neck Surg. 2002; 127: 546-548.

29. Bernatowska E, Mikoluc B, Krzeski A, Piatosa B, Gromek I. Chronic rhinosinusitis in primary antibody immunodeficient patients. Int J Pediatr Otorhinolaryngol. 2006; 70: 1587-1592.

30. Chester AC, Antisdel JL, Sindwani R. Symptom-specific outcomes of endoscopic sinus surgery: a systematic review. Otolaryngol Head Neck Surg. 2009; 140: 633-639.

31. Lund VJ, Kennedy DW. Staging for rhinosinusitis. Otolaryngol Head Neck Surg. 1997; 117: S35-S40.

32. Hessler JL, Piccirillo JF, Fang D, et al. Clinical outcomes of chronic rhinosinusitis in response to medical therapy: results of a prospective study. Am J Rhinol 2007; 21: 10-18.

33. Stewart MG, Sicard MW, Piccirillo JF, Az-Marchan PJ. Severity staging in chronic sinusitis: are CT scan findings related to patient symptoms? Am J Rhinol. 1999; 13: 161-167.

34. Bhattacharyya N. Relationship between mucosal inflammation, computed tomography, and symptomatology in chronic rhinosinusitis without polyposis. Ann Otol Rhinol Laryngol. 2008; 117: 517-522.

35. Briggs RD, Wright ST, Cordes S, Calhoun KH. Smoking in chronic rhinosinusitis: a predictor of poor long-term outcome after endoscopic sinus surgery. Laryngoscope. 2004; 114: 126-128.

36. Das S, Becker AM, Perakis H, Prosser JD, Kountakis SE. The effects of smoking on short-term quality of life outcomes in sinus surgery. Laryngoscope. 2007; 117: 2229-2232.

37. Hopkins C, Browne JP, Slack R, Lund V, Brown P. The LundMackay staging system for chronic rhinosinusitis: how is it used and what does it predict? Otolaryngol Head Neck Surg. 2007; 137: 555-561.

38. Bascom R, Kesavanathan J, Permutt T, Fitzgerald TK, Sauder L, Swift DL. Tobacco smoke upper respiratory response relationships in healthy nonsmokers. Fundam Appl Toxicol. 1996; 29: 86-93.

39. Bascom R, Kesavanathan J, Fitzgerald TK, Cheng KH, Swift DL. Sidestream tobacco smoke exposure acutely alters human nasal mucociliary clearance. Environ Health Perspect. 1995; 103: 10261030 .

40. Lieu JE, Feinstein AR. Confirmations and surprises in the association of tobacco use with sinusitis. Arch Otolaryngol Head Neck Surg. 2000; 126: 940-946.

41. Corey JP, Bumsted RM. Revision endoscopic ethmoidectomy for chronic rhinosinusitis. Otolaryngol Clin North Am. 1989; 22: 801808 .

42. Lazar RH, Younis RT, Long TE, Gross CW. Revision functional endonasal sinus surgery. Ear Nose Throat J. 1992; 71: 131-133.

43. Lee JY, Lee SW, Lee JD. Comparison of the surgical outcome between primary and revision endoscopic sinus surgery for chronic rhinosinusitis with nasal polyposis. Am J Otolaryngol. 2008; 29: 379-384.

44. Matthews BL, Smith LE, Jones R, Miller C, Brookschmidt JK. Endoscopic sinus surgery: outcome in 155 cases. Otolaryngol Head Neck Surg. 1991; 104: 244-246.

45. Jorrisen M, Bachert C. Effect of corticosteroids on wound healing after endoscopic sinus surgery. Rhinology. 2009; 47: 280-286.

\section{Rafał Chmielewski M.D.}

Department of Otolaryngology

Warsaw Medical University

ul. Banacha 1a

02-097 Warsaw

Poland

Tel: +48-22-599-2521

Fax: +48-22-599-2523

E-mail: rafalchmielewski@gmail.com 